\title{
Radiation sensitivity of microelectromechanical system devices
}

\author{
Herbert R. Shea \\ Ecole Polytechnique Fédérale de Lausanne \\ Microsystems for Space Technologies Laboratory \\ Rue Jaquet Droz 1 \\ CP 526 \\ CH-2002 Neuchâtel, Switzerland \\ E-mail: herbert.shea@epfl.ch
}

\begin{abstract}
The sensitivity of microelectromechanical system (MEMS) devices to radiation is reviewed, with an emphasis on radiation levels representative of space missions rather than of operation in nuclear reactors. As a purely structural material, silicon has shown no mechanical degradation after radiation doses in excess of 100 Mrad. MEMS devices, even when excluding control/readout electronics, have, however, failed at doses of only $20 \mathrm{krad}$, though some devices have been shown to operate correctly for doses greater than 10 Mrad. Radiation sensitivity depends strongly on the sensing or actuation principle, device design, and materials, and is linked primarily to the impact on device operation of radiation-induced trapped charge in dielectrics. MEMS devices operating on electrostatic principles can be highly sensitive to charge accumulation in dielectric layers, especially for designs with dielectrics located between moving parts. In contrast, thermally and electromagnetically actuated MEMS are much more radiation tolerant. MEMS operating on piezoresitive principles start to slowly degrade at low doses, but do not fail catastrophically until doses of several Mrad. A survey of all published reports of radiation effects on MEMS is presented, as well as a summary of techniques that can improve their radiation tolerance. (c) 2009 Society of Photo-Optical Instrumentation Engineers. [DOI: 10.1117/1.3152362]
\end{abstract}

Subject terms: radiation; dielectric charging; radiation hardening; space; spacecraft; electrostatic; MEMS.

Paper 08182SSR received Dec. 1, 2008; revised manuscript received Feb. 10, 2009; accepted for publication Feb. 16, 2009; published online Jul. 2, 2009.

\section{Introduction}

Microelectromechanical systems (MEMS) have been commercially adopted in large volumes in a number of Earthbound applications, some of the most common being accelerometers for automotive applications, pressure sensors for engine management, and micromirror arrays for display applications.

Combining low mass, low power consumption, small volume, and possible integration with control and sense electronics, MEMS seem ideal for space applications. Currently, MEMS serve as replacements for bulkier sensors (e.g., accelerometers or gyroscopes), and as enabling technology on science missions that could not proceed without them [e.g., the atomic force microscope (AFM) on the Phoenix mission on Mars $\left.{ }^{1}\right]$. In the medium term, MEMS technology will allow subsystems (such as phased array antennae, Earth sensors, optical switches, and low-thrust propulsion systems) to be reduced significantly in size and mass. In the longer run, MEMS can enable new classes of extremely small, intelligent, self-managing and relatively low-cost batch-produced picosatellites operating in constellations.

Considering the high reliability of MEMS used on Earth in safety-critical applications, and the reduction in part count made possible by highly integrated MEMS, it is likely that a spacecraft based on carefully designed MEMS could be more reliable than the conventional solution. One

$1932-5150 / 2009 / \$ 25.00$ ๑ 2009 SPIE major difference between operation on Earth and in space is the radiation level. ${ }^{2}$ Other space-specific reliability concerns are thermal cycling and thermal shocks, vibration and mechanical shock at launch and at stage/heat shield separation, and operation in very high vacuum. We focus on the effect of radiation on MEMS. This is of particular concern for small satellites that have less shielding than larger satellites, yet it is these small satellites that stand to gain most from MEMS technologies and hence adopt them soonest. MEMS can also encounter a high radiation environment in nuclear reactors. Since nearly all published work on the effect of radiation on MEMS has focused on space applications, we review here primarily the effect of radiation levels and types applicable to a variety of space missions.

Consisting primarily of trapped electrons, trapped and solar protons, cosmic rays, and of bremsstrahlung (created when energetic particles strike the spacecraft), the space radiation environment is strongly time and position dependent. The dose received by the spacecraft (SC) thus depends by orders of magnitude on the SC orbit/trajectory, time of launch, and duration of the mission. Although the radiation environment is complex, there exist excellent software tools (e.g., Ref. 3) to model the dose and type of radiation a SC will encounter in its lifetime.

Considerable effort has been expended over the past 50 years to devise techniques to test the suitability of electronics components for use in high-radiation environments, as well as design techniques to develop radiation-tolerant electronics and optics. The physics of how different energetic particles interact with matter, the types of damage that 
are caused, and the influence on most electronic devices, optical components, and mechanical parts is well understood, ${ }^{4}$ and there exist well-established test procedures for space applications, for instance Refs. 5 and 6. Due in part to the relative immaturity of the MEMS field, but primarily due to the vast range of materials, technologies, and applications that MEMS cover, there is no standard test procedure for the effect of radiation on MEMS, though there are some proposed approaches. ${ }^{7}$

Even at the high end of space mission doses, the mechanical properties of silicon and metals are mostly unchanged (Young's modulus, yield strength not significantly affected). Silicon as a structural material can be viewed as intrinsically radiation hard. This makes most MEMS devices mechanically radiation tolerant by default. For MEMS devices operating on electrostatic principles, the main failure mode is the accumulation of charge in dielectric layers due to ionizing radiation. The trapped charge leads to device failure, for instance large changes in calibration of capacitive accelerometers, or device failure due to stiction initiated by electrostatic forces from the trapped charge. Of concern are also the drive/control electronics, which may need to be shielded or built with radiationtolerant technologies.

We summarize the broad range of possible MEMS applications in space in Sec. 2. The space radiation environment is briefly presented in Sec. 3. An overview of radiation effects on materials is given in Sec. 4, followed in Sec. 5 by a review of all published data of the effects of radiation (gamma, x-rays, proton, electron, and alpha particles) on MEMS devices. Suggestions for radiation-hardening MEMS are given in Sec. 6.

\section{Overview of Space Applications of Microelectromechanical Systems}

MEMS have been proposed for a number of space applications, either as lighter and smaller replacement parts or as entire new systems. ${ }^{8}$ A few MEMS components have been flown in space, mostly as technology demonstrators. In the near future, MEMS that are available as commercial offthe-shelf (COTS) parts, as well as those that are crucial for enabling technologies for science missions, will be flown. We briefly list some of the more developed areas next.

Inertial navigation. Accelerometers and gyroscopes are the most mature MEMS devices used in space, used to instrument launchers as well as rovers. Since these devices are available as COTS parts for commercial and military applications, it is likely that they can be requalified for space by derating (for derating procedure, see Ref. 9). There have been several studies addressing this issue for space. ${ }^{10-12}$ COTS accelerometers have been shown to survive 1000 temperature cycles from $-65^{\circ} \mathrm{C}$ to $+150{ }^{\circ} \mathrm{C}$, as well as 30,000 mechanical shocks of $2000 \mathrm{G}$.

Bolometers. Micromachining allows thermal isolation of small detectors, enabling both uncooled and cooled bolometer arrays to offer very high performance. Such devices are commercially available for Earth-based IR detector applications. A MEMS bolometer from JPL/Caltech (Pasadena, California) ${ }^{8}$ was launched on the ESA/NASA Planck mission in May 2009.
Optical instrumentation. The near-infrared spectrometer (NIR-Spec) on the James Webb Space Telescope will use MEMS-based microshutters manufactured by NASA/ GSFC.

Atomic force microscope. An AFM (FAMARS ${ }^{13}$ ) was one of the scientific instruments on the 2008 Phoenix $^{1}$ mission to Mars. The piezoresistive single crystal silicon based AFM operated flawlessly on Mars. The AFM was not radiation hardened but its control electronics were.

Radiofrequency switches and variable capacitors. MEMS technologies enable the fabrication of very compact lowloss RF switches, as well as capacitors with a large tuning range. Such devices are just starting to be commercially available, for example from Radant MEMS ${ }^{14}$ (Stow, Massachusetts). RF switches were flown in space on the OPAL Picosats in 2000. They were stored in orbit for a year, and then successfully operated. ${ }^{15}$ IMEC, in Leuven, Belgium, have led several studies into the reliability of RF MEMS for space. ${ }^{16}$

Optical switching and communication. The boom in optical MEMS between 1999 and 2002 led to the development of large optical switch matrices based on MEMS devices. There are ongoing European Space Agency (ESA) projects on the development and qualification methodology of such MEMS switches for space. There have been studies of COTS parts, ${ }^{17}$ but no devices have been flown.

Propulsion. There are several approaches to using MEMS for propulsion in space, reflecting the different propulsion technologies such as cold gas, hot gas, and electric propulsion. One approach is to miniaturize an ion thruster by micromachining and integrating electron source, gas handling, nozzle and other components (see for example Ref. 18). An approach to an integrated array of MEMS colloid thrusters based on bonded SOI wafers, emitting ions extracted from ionic liquids with high specific impulse, is described in Refs. 19 and 20. A different approach is to microfabricate arrays of explosive microthrusters, which consist of micromachined cavities filled with solid propellant. A micromachined hotplate is bonded on top of each cavity to allow ignition of the microthrusters one at a time. ${ }^{21,22}$ Finally, silicon machining has been used to fabricate compact cold gas thrusters consisting of bonded Si chips to form a reaction chamber and compact nozzle. ${ }^{23}$

Bio-and microfluidics. SU8 and other polymers, as well as Pyrex and silica, are used to fabricate microfluidic devices, including channels, nozzles, and pumps. Such devices are principally being developed for medical or pharmaceutical (lab-on-a-chip) applications, ${ }^{24}$ but could eventually be used as part of a propulsion system.

\section{Space Radiation Environment}

The radiation environment in space is complex, and is concisely described in Refs. 2, 25, and 26. Software models are available for the different types of radiation that can be encountered. Software packages (e.g., SPENVIS ${ }^{3}$ ) exist that combine these different models, allowing rapid determination of the dose and type of radiation exposure for 
Table 1 Representative annual radiation doses for LEO and GEO.

\begin{tabular}{lcl}
\hline \hline Trajectory, shielding & Predominant particles & $\begin{array}{l}\text { Dose deposited } \\
\text { per year }\end{array}$ \\
\hline LEO, outside S/C & Trapped electrons & $>100 \mathrm{krad}$ \\
LEO, 4-mm Al equivalent & Trapped protons & $1 \mathrm{krad}$ \\
GEO, outside S/C & Trapped electrons & $>10,000 \mathrm{krad}$ \\
GEO, 4-mm Al equivalent & $\begin{array}{l}\text { Bremsstrahlung+ } \\
\text { solar protons }\end{array}$ & $10 \mathrm{krad}$ \\
\hline \hline
\end{tabular}

Earth orbits. Models also exist for deep space, but have less data to support them. The main types of radiation encountered near Earth consist of the following.

- Trapped radiation: energetic electrons and protons magnetically trapped around the earth (Van Allen belts). They consist of electrons of energy up to a few $\mathrm{MeV}$, and protons of up to several hundred $\mathrm{MeV}$.

- Solar energetic particles: mostly highly energetic protons, up to $300 \mathrm{MeV}$. The intensity varies greatly in time, especially the 11-year solar cycle, since the proton flux is associated with solar flares. UV and x-ray burst are also produced, as well as solar cosmic rays.

- Galactic cosmic-rays: continuous low flux of highly energetic (1 MeV to $1 \mathrm{GeV}$ ) particles, mostly protons and alpha particles, but also heavy ions.

- Secondary radiation: radiation generated when the previous radiation interacts with materials in the spacecraft, notably with shielding. Includes primarily electron-induced bremsstrahlung, but also secondary electrons and other particles such as secondary neutrons.

The global effect of the many different types of radiation on components can be summarized by the quantity of energy deposited by the radiation. The SI unit is the Gray $(1 \mathrm{~J} / \mathrm{kg})$, but the unit $\mathrm{rad}\left(1 \mathrm{rad}=10^{-2} \mathrm{Gray}\right)$ is still in common use.

The energy deposited varies as a function of time and location of the SC. Accurate models can predict the quantity of energy deposited as a function of the trajectory. Table 1 gives approximate values of energy deposited in a component for a low Earth orbit (LEO) and for a geostationary orbit (GEO) without shielding and with shielding equivalent to $4 \mathrm{~mm}$ thickness of aluminium.

It is clear that unshielded components face a much harsher radiation environment that shielded ones. The highest deposited dose is on solar panels and the external surfaces of the SC. On large spacecrafts, it is unlikely that MEMS will be directly exposed to space, so that lower radiation values will be expected (with the exception of sun sensors and thermal control louvers. ${ }^{27}$ ) On small ( 1 to $100 \mathrm{~kg}$ ) satellites, the situation is quite different, with little mass that can be dedicated to shielding and a higher reliance on MEMS, leading to higher doses and greater importance in understanding the effect of radiation on MEMS.

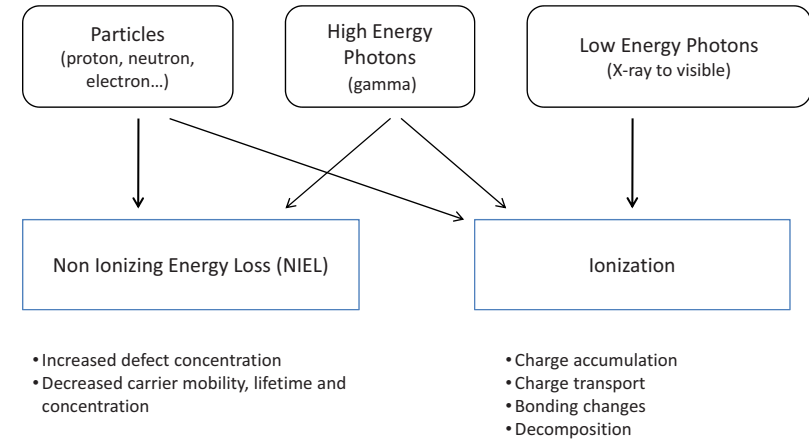

Fig. 1 Summary of radiation-induced degradation effects, ignoring transient effects, adapted from Table 5.1 of Ref. 25.

Space missions typically last several years, and operate in a radiation environment with dose rates of the order $1 \mathrm{rad} / \mathrm{h}$. Testing, however, must be done in hours or days (dose rates from $36 \mathrm{rad} / \mathrm{h}$ to $36 \mathrm{krad} / \mathrm{h}$ are commonly used for ${ }^{60} \mathrm{Co}$ irradiation). Despite the complexity of the actual space radiation environment, accelerated radiation testing methods have been developed using monoenergetic particle, whose relevance and suitability have been amply demonstrated for microelectronic devices. There is, however, no standard testing procedures established for MEMS, though studies are ongoing.

\section{Radiation Effects on Materials}

The effect of radiation on materials is well described in several books such as in Ref. 4. We briefly summarize in this section the main degradation processes and effects on different materials to serve as a foundation for a MEMScentered analysis in the following section.

\subsection{Degradation Processes}

Energetic particles and photons cause damage by transferring energy to the materials they penetrate. The energy loss mechanisms are complex, but the type of damage can be classified in two consequences: 1. atomic displacement and 2. ionization. Figure 1 provides an overview of the effects that radiation can have on devices.

\subsubsection{Nonionizing radiation loss}

A fraction of the energy transferred to the target from energetic particles or even from photons results in the transfer of momentum to atomic nuclei, which can result in atoms being moved from their rest position in the lattice, leaving vacancies or defects behind. The process of atomic displacement is referred to as "bulk damage,"4 Even photons of sufficient energy can give rise to this nonionizing radiation loss (NIEL), or displacement damage.

Displacement damage has a number of consequences. The most relevant for electronic devices is the reduction in minority carrier lifetime, the reduction of carrier mobility, and the removal of carriers (by interaction with defects). The damage caused by most particles is of the same general type. For silicon, equivalence has been shown between a fluence of $1-\mathrm{MeV}$ electrons and different fluences of other particles. 


\subsubsection{Ionization}

Most of the energy lost from radiation interacting with an absorber is ultimately converted to electron-hole pairs (the energy required is only $18 \mathrm{eV}$ for $\mathrm{SiO}_{2}$ ). Electrons and holes have very different mobilities. The electrons and holes increase the conductivity of the sample (even of insulators), and the holes can become trapped in insulators $\left(\mathrm{SiO}_{x}, \mathrm{SiN}_{x}\right)$, leading to serious degradation of MOS and MEMS devices. This total ionizing radiation dose (TID) leads to an accumulation of electrically active defects. The biasing of a sample is important because the electric field from the bias will drive the electrons and holes, and thus change the effect on the device of ionizing radiation.

In polymers, the ionization can break bonds and even create new ones.

\subsubsection{Single event effects}

Single event effects (SEE) are not a damage mechanism like NIEL or ionization, but are an important manifestation in microelectronic circuits from the effect of energetic particles. SEE include single event upsets (soft errors, which are not destructive to the device, though may cause bit flips and hence data corruption), and single event latchup and single event burnout, which are or can be destructive to the transistor or entire circuit.

\subsection{Degradation Consequences}

The consequences of damage depend on whether the damage is due to atomic displacement or to ionization, whether the effects are transient or long lived, and what type of material absorbed the radiation (we distinguish between metal, semiconductor, and insulator). Additionally, one can also distinguish between changes in the mechanical versus electrical properties of the materials.

\subsubsection{Metals}

There are no reports of important metal degradation by radiation in space. ${ }^{25}$ In nuclear reactor cores, the neutron fluxes are high enough to significantly reduce the mechanical strength of metals, or render them brittle. For space missions, metals are deemed to be radiation tolerant.

\subsubsection{Semiconductors}

Displacement damage leads to electrical and mechanical changes. The electrical changes are due to the change in minority carrier lifetime and concentration, which can have an important effect on p-n junctions (rectifiers and bipolar transistors, as well as solar cells). FET and MOS devices are much less sensitive to this effect.

Concerning mechanical changes, even at the high end of typical doses for space (Mrad), the amount of damage to silicon is rather small (defects, clusters), and the Young's modulus is not markedly changed. For electronics and packaging, the effect can be ignored. For MEMS devices such as resonators, which are sensitive to ppm change in Young's modulus, further investigation is required. High energy radiation produces electron-hole pairs, leading to photocurrents lasting as long as the radiation persists. The dose rate rather than the dose is the important parameter, since the photocurrents are proportional to the rate. Latchup and logic upsets (not due to cosmic rays, but due to ioniza- tion of semiconductors) require dose rates of greater than $10^{7} \mathrm{rad} / \mathrm{s}$, i.e., $10^{6}$ times higher than what typical orbiting spacecraft experience.

\subsubsection{Insulators}

In optical materials, displacement damage leads to color centers. For electronic or structural materials, displacement damage leads only to very small effects (compared to semiconductors), because dielectrics are typically glassy (amorphous), and there is thus no ordered lattice to disrupt with defects, clusters, or dislocations. So the dielectric can retain its good insulating properties even when a few atoms are displaced. Also, doping levels are not important, unlike semiconductors where it is a crucial parameter.

Ionization of insulators has a major impact on microelectronic devices, in particular for LSI and VLSI MOS ICs (and the effect is even more pronounced on the newer devices with gate oxides of thickness of order $1 \mathrm{~nm}$ and trace widths of order $60 \mathrm{~nm}$, which is one reason why ICs for use in space are generally based on older technologies with thicker gate oxides and larger features). The harmful effects of ionization in dielectrics are diverse, but are related either to a dramatic decrease in resistance of the dielectric, or to accumulation of trapped charge. For electrostatically actuated MEMS devices, trapped charge can cause device failure, as seen in the next section.

\section{Survey of Radiation Tests Performed on Microelectrochemical System Devices}

\subsection{Introduction}

MEMS devices can operate on a wide variety of physical principles for sensing and for actuation, the most common being electrostatic, thermal, magnetic, and piezoelectric. Other principles that are less widespread include chemical reactions, electrophoresis, and capillary force. The wide variety of materials and physical principles used make it difficult to make general statements about MEMS reliability and radiation sensitivity. Different sensing and actuation principles are shown next to be very different in their radiation tolerance.

A comprehensive review of MEMS failure modes can be found in Refs. 28-30, and references therein, and in Refs. 7 and 31 for space-specific aspects. Failure modes depend on the materials used for the device, the fabrication approach, the packaging, and of course the design. Most failure modes can be minimized through proper design and packaging. One should note, however, that designing for reliability can involve trade-offs, for instance sacrificing a degree of performance for longer lifetime, or using a more complex process fabrication to slow device degradation.

Few radiation tests have been performed on MEMS devices (less than 20 published papers, see Table 2 for an overview of minimum dose for failure and failure modes for different MEMS devices). The degradation of integrated circuits (CMOS, bipolar, etc.) with radiation is well documented. Most radiation tests on MEMS have focused on the effects of radiation on the MEMS sensor or actuator, but have often been limited by failure of the electronics.

On the low-tolerance end, one finds that most electrostatically operated MEMS devices degrade between 30 and $100 \mathrm{krad}$, unless special steps are taken to shield or remove 
Table 2 Review of reported sensitivity of MEMS devices to radiation. Test structures are not included in this table. Co-60 $\gamma$ indicates the 1.17-MeV and 1.33-MeV gamma ray from a ${ }^{60} \mathrm{Co}$ source.

\begin{tabular}{|c|c|c|c|c|c|}
\hline MEMS device & $\begin{array}{l}\text { Actuation } \\
\text { type }\end{array}$ & $\begin{array}{l}\text { Minimum dose } \\
\text { for failure }\end{array}$ & Radiation type & Failure mode & Reference \\
\hline $\begin{array}{l}\text { Analog device } \\
\text { ADXL } 150\end{array}$ & $\begin{array}{l}\text { Electrostatic } \\
\text { (comb-drive) }\end{array}$ & 27 krad $(\mathrm{Si})$ & Co-60 $\gamma$ & Not investigated & 42 \\
\hline $\begin{array}{l}\text { Analog device } \\
\text { ADXL } 150\end{array}$ & $\begin{array}{l}\text { Electrostatic } \\
\text { (comb-drive) }\end{array}$ & $\begin{array}{l}\text { Highly tolerant } \\
\text { (no failures seen) }\end{array}$ & $\begin{array}{l}\text { Infrared laser, } \\
5.5 \mathrm{~nJ} \text { (SEE) }\end{array}$ & Not investigated & 42 \\
\hline $\begin{array}{l}\text { Analog Devices } \\
\text { ADXL } 50\end{array}$ & $\begin{array}{l}\text { Electrostatic } \\
\text { (comb-drive) }\end{array}$ & $25 \mathrm{krad}(\mathrm{Si})$ & Co-60 $\gamma$ & $\begin{array}{c}\text { Dielectric charging in } \\
\text { device }\end{array}$ & 33 \\
\hline $\begin{array}{l}\text { Analog Devices } \\
\text { ADXL } 50\end{array}$ & $\begin{array}{l}\text { Electrostatic } \\
\text { (comb-drive) }\end{array}$ & $>50 \operatorname{krad}(\mathrm{Si})$ & $\begin{array}{l}\text { SEM localized e- } \\
\text { beam } 30 \mathrm{keV}\end{array}$ & $\begin{array}{c}\text { Dielectric charging in } \\
\text { device }\end{array}$ & 33 \\
\hline $\begin{array}{l}\text { Analog Devices } \\
\text { ADXL } 50\end{array}$ & $\begin{array}{l}\text { Electrostatic } \\
\text { (comb-drive) }\end{array}$ & $100 \operatorname{krad}(\mathrm{Si})$ & 5.5-MeV protons & $\begin{array}{l}\text { Dielectric charging in } \\
\text { device }\end{array}$ & 33 \\
\hline $\begin{array}{l}\text { Analog Devices } \\
\text { ADXL } 50\end{array}$ & $\begin{array}{l}\text { Electrostatic } \\
\text { (comb-drive) }\end{array}$ & 100 krad $(\mathrm{Si})$ & $\begin{array}{l}155-\mathrm{MeV} \\
\text { protons }\end{array}$ & $\begin{array}{l}\text { Proton displacement } \\
\text { in reference circuit }\end{array}$ & 33 \\
\hline $\begin{array}{l}\text { Analog Devices } \\
\text { ADXL } 50\end{array}$ & $\begin{array}{l}\text { Electrostatic } \\
\text { (comb-drive) }\end{array}$ & $20 \mathrm{krad}(\mathrm{Si})$ & $\begin{array}{l}65-\mathrm{MeV} \text { protons } \\
\text { and heavy ion }\end{array}$ & $\begin{array}{c}\text { Dielectric charging in } \\
\text { device }\end{array}$ & 41 and 32 \\
\hline $\begin{array}{l}\text { Motorola } \\
\text { XMMAS40G }\end{array}$ & Electrostatic & $4 \operatorname{krad}(\mathrm{Si})$ & Co-60 $\gamma$ & $\begin{array}{l}\text { Failure of } \mathrm{CMOS} \\
\text { readout circuit }\end{array}$ & 33 \\
\hline $\begin{array}{l}\text { Sandia } \\
\text { microengines }\end{array}$ & $\begin{array}{l}\text { Electrostatic } \\
\text { (comb-drive) }\end{array}$ & $\begin{array}{c}1 \text { to } 100 \text { Mrad } \\
\left(\mathrm{SiO}_{2}\right) \text { bias } \\
\text { dependent }\end{array}$ & $\begin{array}{l}\text { 2-MeV protons, } \\
5 \text { to } 25-\mathrm{keV} \\
\text { electrons, } \\
\text { 10-keV x-rays }\end{array}$ & Dielectric charging & 35 \\
\hline $\begin{array}{l}\text { Endevco } \\
\text { accelerometer } \\
\text { 7264B-500T }\end{array}$ & Piezoresistive & $>30 \mathrm{Mrad}$ & Co-60 $\gamma$ & $\begin{array}{l}\text { Trapped charge, } \\
\text { depletion of minority } \\
\text { carriers }\end{array}$ & 48 \\
\hline $\begin{array}{l}\text { Kulite pressure } \\
\text { transducers XTE- } \\
190-25 A\end{array}$ & Piezoresistive & $\begin{array}{l}7 \text { Mrad to }>20 \\
\text { Mrad, sample } \\
\text { dependent }\end{array}$ & Co-60 $\gamma$ & $\begin{array}{l}\text { Trapped charge, } \\
\text { depletion of minority } \\
\text { carriers }\end{array}$ & 48 and 50 \\
\hline $\begin{array}{l}\text { DSTO/Analatom Si } \\
\text { strain gauge }\end{array}$ & Piezoresistive & $10^{16}$ protons $/ \mathrm{cm}^{2}$ & 3.5-MeV protons & $\begin{array}{l}\text { Decrease in carrier } \\
\text { density and mobility } \\
\text { (NIEL) }\end{array}$ & 49 \\
\hline $\begin{array}{l}\text { Sercalo } 1 \times 2 \text { optical } \\
\text { switch }\end{array}$ & $\begin{array}{l}\text { Electrostatic } \\
\text { (comb-drive) }\end{array}$ & $>22.5 \operatorname{krad}(\mathrm{Si})$ & Co-60 $\gamma$ & No failures seen & 43 \\
\hline $\begin{array}{l}\text { Boston } \\
\text { Micromachines Co. } \\
\text { Poly-Si } \\
\text { Micromirrors array }\end{array}$ & $\begin{array}{l}\text { Electrostatic } \\
\text { (parallel-plate) }\end{array}$ & $3 \mathrm{Mrad}(\mathrm{Si})$ & Co-60 $\gamma$ & No failure seen & 45 \\
\hline $\begin{array}{l}\text { Rockwell Scientific } \\
\text { Co. } \\
\text { if switch }\end{array}$ & $\begin{array}{l}\text { Electrostatic } \\
\text { (parallel-plate) }\end{array}$ & $30 \mathrm{krad}(\mathrm{GaAs})$ & Co-60 $\gamma$ & $\begin{array}{c}\text { Dielectric charging in } \\
\text { device (strongly } \\
\text { geometry } \\
\text { dependent) }\end{array}$ & 34 \\
\hline $\begin{array}{l}\text { FBK-IRST ohmic if } \\
\text { switch }\end{array}$ & $\begin{array}{l}\text { Electrostatic } \\
\text { (parallel-plate) }\end{array}$ & $\begin{array}{c}\text { 10-Mrad }\left(\mathrm{SiO}_{2}\right) \\
\text { proton } \\
\text { 1-Mrad }\left(\mathrm{SiO}_{2}\right) \text { x-ray }\end{array}$ & $\begin{array}{l}\text { 2-MeV protons } \\
\text { 10-keV x-ray }\end{array}$ & $\begin{array}{l}\text { Both NIEL and } \\
\text { ionizing damage }\end{array}$ & 39 \\
\hline $\begin{array}{l}\text { VTI SCA } 600 \\
\text { accelerometer }\end{array}$ & $\begin{array}{l}\text { Electrostatic } \\
\text { (parallel plate) }\end{array}$ & $50 \mathrm{krad}(\mathrm{Si})$ & Co-60 $\gamma$ & Not investigated & 42 \\
\hline $\begin{array}{l}\text { VTI SCA } 600 \\
\text { accelerometer }\end{array}$ & $\begin{array}{l}\text { Electrostatic } \\
\text { (parallel plate) }\end{array}$ & $\begin{array}{l}\text { Not quantified, } \\
\text { but low }\end{array}$ & $\begin{array}{l}\text { Infrared laser, } \\
5.5 \mathrm{~nJ} \text { (SEE) }\end{array}$ & $\begin{array}{l}\text { Due to latch-up } \\
\text { CMOS electronics }\end{array}$ & 42 \\
\hline
\end{tabular}


Table 2 (Continued.)

\begin{tabular}{|c|c|c|c|c|c|}
\hline MEMS device & $\begin{array}{l}\text { Actuation } \\
\text { type }\end{array}$ & $\begin{array}{l}\text { Minimum dose } \\
\text { for failure }\end{array}$ & Radiation type & Failure mode & Reference \\
\hline NASA/GSFC & $\begin{array}{c}\text { Electrostatic } \\
\text { and electromagnet } \\
\text { IC }\end{array}$ & $\begin{array}{l}10 \text { to }>200 \text { krad } \\
\text { (Si) depending on } \\
\text { drive voltage }\end{array}$ & Co-60 $\gamma$ at $60 \mathrm{~K}$ & $\begin{array}{l}\text { Charge trapping } \\
\text { (dielectric charging) }\end{array}$ & 46 \\
\hline $\begin{array}{l}\text { Polysilicon } \\
\text { electrothermal } \\
\text { actuator and } \\
\text { bimorph } \\
\text { cantilevers }\end{array}$ & $\begin{array}{c}\text { Electrothermal } \\
\text { and CTE } \\
\text { mismatch }\end{array}$ & $>1 \operatorname{Mrad}(\mathrm{Si})$ & Co-60 $\underset{x \text {-ray }}{\gamma} 50 \mathrm{keV}$ & No failure seen & 51 \\
\hline $\begin{array}{l}\text { Purdue wireless } \\
\text { microdosimeter }\end{array}$ & $\begin{array}{c}\text { Electrostatic } \\
\text { (parallel plate) }\end{array}$ & $\begin{array}{c}\text { Tested up to } 650 \\
\text { Mrad }\end{array}$ & Co-60 $\gamma$ TID & No failure seen & 59 \\
\hline
\end{tabular}

the dielectric materials to render the device insensitive to charge build-up in dielectric layers. Tests on accelerometers and rf switches showed a marked change in calibration at doses above $30 \mathrm{krad}^{32-34}$ Those failures were attributed to trapped charge in dielectric films. These doses are for unpackaged devices, so that the sensor element is directly irradiated. Similar doses on packaged devices would lead to significantly less damage.

On the other extreme, microengines from Sandia National Laboratories in Albuquerque, New Mexico, were reported to only change their behavior at doses of order $10 \mathrm{Mrad}$, in some cases over $1 \mathrm{Grad}^{35}$ Those devices did contain dielectrics $\left(\mathrm{SiO}_{2}\right.$ and $\left.\mathrm{SiN}_{x}\right)$, but not in a geometry where charging could directly influence device operation.

Mechanical and electrical properties are tightly linked in MEMS devices. Failure modes are grouped in Table 2 as mechanical related to displacement damage, mechanical related to ionization, and electrical due to charge trapping.

\subsection{Mechanical Failures Due to Displacement Damage}

Even at the high end of space mission doses (several Mrad corresponding to 10 years in a GPS orbit), the mechanical properties of silicon and metals are mostly unchanged, e.g., Young's modulus and yield strength are not significantly affected. Silicon is thus considered a structural material that is intrinsically radiation hard. This makes most Si-based MEMS devices radiation hard with respect to purely mechanical failures. Indeed, there have been no reports of mechanical changes in MEMS devices due to displacement damage.

However, this perception is an oversimplification, and is only true for devices where the Young's modulus needs to be stable to a few parts per thousand, for example for MOEMS, or devices that operate in two well-defined states such as rf switches. It is probably not correct for rf oscillators where 10-ppm stability is required of the resonance frequency, which is proportional to the square root of the Young's modulus. This issue has not been experimentally addressed to date.

High energy protons and ions tend to build clusters at the stopping power range, which can modify the mechanical properties of small beams bent to high stress levels. At high strain gradients, diffusion is highly enhanced in small beams, and therefore these parts have to be carefully tested for mobile defects, an important cause of aging.

Stark $^{7}$ writes that, "it is known that high $\mathrm{Z}$ radiation can lead to fracturing by creating massive disorder within the crystal lattice. Since this radiation source is common in the space environment, it needs to be investigated." One promising technique to investigate and quantify damage due to irradiation is double and triple crystal x-ray diffractometry, which has been used, for example, to measure the damage due to deep reactive ion etching (DRIE) of silicon MEMS parts, ${ }^{36}$ as well as for space applications. ${ }^{37}$

Though not strictly speaking a MEMS device, the sensitivity of quartz resonators to radiation has been studied, and a review can be found in Ref. 38. The resonance frequency of a quartz resonator changes with radiation, because the elastic properties are modified when radiation changes the position of weakly bound charge compensators (such as $\mathrm{H}^{+}, \mathrm{Li}^{+}$, or $\mathrm{Na}^{+}$) around substitutional defects, which also reduces the quality factor. This effect can be as large at $10 \mathrm{ppm}$ for natural quartz at a 1-Mrad dose. ${ }^{38}$ Pure crystals are much less affected.

Tazzoli et al. ${ }^{39}$ report on the effect of $2-\mathrm{MeV}$ protons on ohmic rf switches, which are electrostatically operated. They observe an important degradation of insertion loss, but only a very small change in actuation voltage, and a complex postirradiation behavior, with a degradation during anneal. They also exposed samples to $10-\mathrm{keV}$ x-rays, which should not produce significant displacement damage, and observed a more pronounced recovery than for protons. They concluded that both NIEL and ionizing damage appear to play a role in the degradation of their switches.

\subsection{Mechanical Failures Related to Ionization}

Schanwald et al. ${ }^{35}$ discuss the possibility that wear processes and friction could be affected by radiation due to the sensitivity of those effects to trapped charge. They also suggest that radiation-induced charging may enhance microwelding across small gaps. They present a model predicting this effect only to occur for gaps smaller than 0.03 to $0.3 \mu \mathrm{m}$, for polysilicon with a $10-\mathrm{nm}$ native oxide. They did not see enhanced microwelding on their irradiated samples, whose smallest gaps were $0.5 \mu \mathrm{m}$, after irradia- 
Table 3 Main failure modes due to dielectric charging versus MEMS actuation principle.

\begin{tabular}{lll}
\hline \hline $\begin{array}{c}\text { MEMS actuation } \\
\text { type }\end{array}$ & $\begin{array}{c}\text { Sensitivity to } \\
\text { dielectric charging }\end{array}$ & $\begin{array}{l}\text { Failure modes due to } \\
\text { dielectric charging }\end{array}$ \\
\hline Electrostatic & $\begin{array}{l}\text { High } \\
\text { (design dependent) }\end{array}$ & $\begin{array}{l}\text { Stuck comb-drive, } \\
\text { snapped-down parallel } \\
\text { plates, change in } \\
\text { calibration of parallel plate } \\
\text { of comb-drive sensors } \\
\text { and actuators }\end{array}$ \\
Magnetic & Very weak & $\begin{array}{l}\text { Change in breakdown } \\
\text { voltage or wire resistance }\end{array}$ \\
Piezo & Weak to medium & $\begin{array}{l}\text { Calibration change } \\
\text { (failures are due to NIEL) }\end{array}$ \\
& & $\begin{array}{l}\text { Change in breakdown } \\
\text { voltage or wire resistance }\end{array}$ \\
\hline \hline
\end{tabular}

tion with $\mathrm{SiO}_{2}$ equivalent doses up to $100 \mathrm{Mrad}$ for $\mathrm{x}$-ray, $5.6 \mathrm{Grad}$ for 5 - to $25-\mathrm{keV}$ electrons, and up to $100 \mathrm{Grad}$ for $2-\mathrm{MeV}$ protons. They measured the quality factor of their microengines and gear rotation rate, and found the devices were operable up to doses of more than $100 \mathrm{Mrad}$ when no electrodes were floating, with radiation effects becoming observable at doses of order $10 \mathrm{Mrad}$.

\subsection{Electrical Failures Due to Charge Accumulation (Total lonizing Dose)}

Most MEMS sensing and actuation schemes require a good electrical contact between a bond pad and the actuator/ sensor electrode of the device, but the exact level of doping is not important as long as the material is sufficiently conductive. Except for piezoresistors or piezoactuators, MEMS typically have no $\mathrm{p}-\mathrm{n}$ junctions or semiconducting regions where doping and carrier concentration plays an important role. There are no active areas like a transistor, only regions where the electric potential needs to be well defined. The dielectric films are thick (of order 0.2 to $1 \mu \mathrm{m}$ ). The conductivity of metal films or semiconductors is unlikely to be significantly changed by any radiation dose or type seen in a foreseeable space mission, with the exception of devices relying on piezoelectric effects. These attributes mean that MEMS can be designed to operate under high radiation doses, and should be relatively insensitive to single event effects.

For dielectrics, ionizing radiation leads to both: 1 . direct charge injection from ionizing radiation, and 2. the creation of deeper traps and possibly more defects, thus making the dielectric even more susceptible to charging from nonradiation-related sources. The influence of the trapped charge depends on the actuation scheme, and very strongly on the geometry, such as the presence or absence of conductive shields to screen the trapped charge. A more subtle effect is the accumulation of charge on the native oxide that coats all silicon surfaces that can give rise to electrostatic forces, or enhanced depletion regions of underlying silicon. Table 3 presents a comparison of estimated sensitivity of different MEMS actuation principles to dielectric charging.

\subsubsection{Electrostatic microelectromechanical system sensors and actuators}

For electrostatic MEMS devices, the main failure mode at high radiation doses is the accumulation of charge in dielectric layers, which first causes a change in the calibration of the device (essentially by applying a quasiconstant electrostatic force), and ultimately can lead to complete failure by a short circuit or continuous (undesired) actuation, even at $0 \mathrm{~V}$. The failure may appear mechanical (e.g., a stuck comb-drive) but the root cause is electrical. For a given device, total ionizing dose (TID) is the main radiation parameter that quantifies the amount of charging.

Photons, electrons, and protons create electron-hole pairs in dielectrics through a number of inelastic scattering mechanisms. The carriers that survive the initial recombination move in response to the local electric field, with electrons being much more mobile than holes. Carriers that become trapped lead to an effectively permanent fixed charge (decay time of hours or days). Details of charging depend on the geometry, secondary electrons emitted from nearby surfaces, and very importantly on the applied bias. Reference 32 provides the first model of how a fixed charge under a comb-drive can lead to a force, and thus to a shift in the output voltage. Reference 32 also developed a model for charge trapping, balancing charging from secondary electron emission with various discharge mechanisms, proving an explanation for why electron and proton irradiation produces trapped charge of opposite polarity, despite both creating electron-hole pairs. Reference 40 provides a model of different charging mechanisms and simulates several geometries.

Existing electrostatic MEMS test data can be classified in three types of electrostatically operated devices:

- comb-drive based sensors (e.g., accelerometers)

- comb-drive actuators (e.g., MOEMS switches, microengines)

- parallel-plate actuators (e.g., rf switches, MOEMS mirrors).

Accelerometers, in particular monolithic comb-drive polysilicon devices manufactured by Analog Devices, have been investigated for TID effects. ${ }^{33,41,42}$ The devices operate by sensing the change in capacitance as a suspended proof mass moves in response to external accelerations. It is thus very sensitive to any static charge in exposed dielectrics, and Knudson et al. ${ }^{41}$ showed the radiation-induced output voltage shift was due to charging of a dielectric under the proof mass. The devices tested under high energy proton and gamma rays show degradation in the 50-krad range (ADXL 50 and ADXL 150). For similar devices where a conducting polysilicon film was placed over the dielectric (ADXL 04), thus effectively electrically shielding any trapped charge from the active device, no radiationinduced degradation was observed up to a dose of 3 Mrad. ${ }^{41}$ The XMMAS40G accelerometer from Motorola tested by Lee et al. ${ }^{33}$ failed after only 4 krad. It is proposed that the failure is due to failure of the CMOS output circuitry rather than the sensor element.

SOI bulk micromachined accelerometers from VTT, Finland, operating by measuring the capacitance between suspended parallel plates, were subjected to gamma rays 
and failed at $50 \mathrm{krad}^{42}$ The sensor was packaged with a readout-ASIC, which was found to latch-up at low doses of infrared laser pulses. It was not determined if the failure at $50 \mathrm{krad}$ was due to the sensor or the ASIC. A nonmonolithic approach (i.e., separate sensor and readout/control ASIC chips in one package) is an appealing approach for rapidly developing radiation tolerant sensors, as it allows choosing a radiation-tolerant ASIC (an easier task since radiation-hard CMOS technology is mature), and focusing the research solely on radiation-hardening the MEMS component.

Sandia National Laboratories (Albuquerque, New Mexico) reports large shifts in CV curves measured on the comb-drives of their polysilicon microengines, reflecting radiation-induced trapped charge in silicon nitride. They report a very important increase in minimum dose required to damage the devices by grounding or applying a voltage to all electrodes. Floating electrodes charge up and cause device failure sooner than electrodes whose potential is externally fixed. ${ }^{35}$

Comb-drive actuators carefully designed with no exposed dielectric between or under moving parts (such as the Sercalo Microtechnology $1 \times 2$ optical switch ${ }^{43}$ or the Sandia microengines ${ }^{35}$ ) have been shown to operate with no change after doses of more than $20 \mathrm{krad}$ and $10 \mathrm{Mrad}$, respectively.

Capacitive rf switches require a dielectric film to separate a fixed electrode from movable membranes. One of the common failure modes of $\mathrm{rf}$ switches is charging of this dielectric due to the large applied electric fields. An rf switch from HRL Laboratories (Malibu, California) was successfully operated dynamically up to a dose of 1 Mrad. $^{44}$ rf switches from Rockwell Scientific Company (Thousand Oaks, California) reported in Ref. 34 showed no change in static characteristics at doses of up to $150 \mathrm{krad}$ for one design developed to reduce dielectric charging. For a more conventional design, the device's calibration started to change at doses of $10 \mathrm{krad}$, although the device continued to operate after doses of $300 \mathrm{krad}$, but with an $80 \%$ increase in required drive voltage. The difference in dose required for degradation between the two devices is due to the different location of the dielectric layers. The configuration that is more radiation tolerant has no dielectric between the moving parts.

A JPL study on MOEMS polysilicon mirrors arrays based on a parallel plate actuation scheme with no exposed dielectric between fixed and moving electrodes showed no damage at doses of 3-Mrad gamma rays. ${ }^{45}$ A microshutter array designed to be used on a spectrometer on the James Webb Space Telescope was tested up to $200 \mathrm{krad},{ }^{46}$ which is the expected lifetime dose expected for the instrument located outside the spacecraft in a second Lagrange point (L2) orbit with little shielding. The device uses an electromagnetic force to move each microshutter, consisting of a multilayer of two dielectrics and two metals, which is then held in place with an electrostatic force. The devices were tested and irradiated at $60 \mathrm{~K}$. The devices were found to be sensitive to gamma rays at $20 \mathrm{krad}$ for the lowest holding voltage used. The severity of the effect was strongly dependent on the holding voltage used. At higher holding voltages $(20 \mathrm{~V})$, no meaningful degradation was seen up to
$200 \mathrm{krad}$, presumably because the larger holding voltage gives rise to a larger electrostatic force, overcoming the force due to trapped charges.

\subsubsection{Nonelectrostatic microelectromechanical system actuators}

A piezoelectric mirror array developed by JPL and Pennsylvania State University based on PZT (lead-zirconate titanate) was functional up to $1 \mathrm{Mrad}$, but at $20 \mathrm{krad}$ started exhibiting changes in mirror deflection compared to unirradiated samples, as well as an important increase in leakage current though the PZT. ${ }^{45}$ The authors developed a model attributing the change in device characteristics to charge trapped in the PZT film.

Polysilicon thermal actuators and gold/polysilicon bimorph cantilevers were investigated by Caffey and Kladitis ${ }^{47}$ under ${ }^{60} \mathrm{Co}$ gamma rays and $50-\mathrm{keV}$ x-rays. No degradation of the devices was observed at $1 \mathrm{Mrad}$, the maximum dose used. This is in line with the understanding that electrothermal devices are for the most part insensitive to dielectric charging, as long as there is no exposed dielectric near the active element.

\subsection{Piezoresistive Sensors}

The radiation sensitivity of micromachined piezoresistive silicon accelerometers and pressure sensors are reported in Refs. 48-51. In all cases an increase in resistance of the piezoresistive elements are observed. Marinaro et al. ${ }^{49}$ found a nearly linear relation between the resistance of the piezoresistor in their single-crystal silicon strain gauge and the fluence of $3.5-\mathrm{MeV}$ protons. They observed changes for fluences of the order of $10^{16} \mathrm{~cm}^{-2}$, corresponding to roughly 10 years in medium Earth orbit (MEO). They attribute the increase in resistance to the NIEL component of the radiation, leading to majority charge removal due to displacement damage serving as trapping centers, and to a reduction in carrier mobility.

Holbert et al. ${ }^{48}$ and McCready et al. ${ }^{50}$ studied the response of piezoresistive MEMS accelerometers and pressure sensors to high gamma-ray doses and pulsed neutrons. They observed a gradual shift in output of Endevco 7264B$500 \mathrm{~T}$ accelerometers with gamma-ray doses up to $73 \mathrm{Mrad}$, with no catastrophic failures, and were able to recalibrate the devices postiradiation. Results were less consistent for Kulite XT-190-25A pressure transducers, with two devices failing suddenly at 7 and $25 \mathrm{Mrad}$, and four others still operating at after $20 \mathrm{Mrad}$, with a shift in output voltage. Holbert et al. ${ }^{48}$ correlate the increase in resistance of the piezoresistors to the formation of trapped hole charges. They show how this trapped charge in the oxide layer surrounding the piezoresistor can induce a depletion region in the semiconductor, thus increasing the device resistance. They conclude that n-type piezoresistors with the largest cross section will be the most radiation tolerant, though there may be a trade-off of sensitivity versus radiation tolerance.

\subsection{Electrical Failures (Single Event Effects)}

Single event effects (SEE) are extremely unlikely to affect MEMS sensors and actuators, as there is no physical means for a single event to have an impact on a MEMS device that 
is typically much too large, would react too slowly, and have thick ( 0.1 to $2 \mu \mathrm{m})$ dielectrics and do not rely on thin depletion regions or $\mathrm{p}-\mathrm{n}$ junctions. Latch-up is not possible in existing MEMS devices, as there is no path for such as current. Of course the control electronics are susceptible to SEE, and appropriate design guidelines must be followed for the electronics.

There has been one investigation of SEE in the control electronics for monolithically fabricated devices (Analog Devices ADXL 150) using a pulsed infrared laser, ${ }^{42}$ showing high tolerance.

\subsection{Test Structures and Substrates}

A number of studies have been done to investigate the radiation effects on materials used in MEMS and on test structures representative of MEMS devices. The density of Pyrex (Corning 7740) and Hoya SD-2 glass substrates was found to increase following neutron irradiation in a reactor core, compacting 10 times less for SD-2 than for Pyrex. ${ }^{52}$ SU-8, a photosensitive epoxy resin commonly used for MEMS, was also exposed to neutron irradiation in a reactor core, and was stable up to doses of $100 \mathrm{Mrad}$, comparable to Kapton polyimide and Mylar PET. ${ }^{53}$

To gain a better understanding of the effect of charging on the dielectric in $\mathrm{rf}$ MEMS switches in space applications, there have been a number of studies using metalinsulator-metal capacitors as test vehicles, exposing them to $5-\mathrm{MeV}$ alpha particles. $^{54,55}$ This technique allows a straightforward measurement of the trapped charge, and can allow for rapid comparison of different dielectrics.

\section{Suggestions for Increasing the Radiation Tolerance of Microelectromechanical Systems}

As seen in the previous section, the difference in sensitivity of MEMS devices to radiation is due primarily to the different impact that trapped charge in dielectric layers has on different actuations schemes and geometries. MEMS operating on electrostatic principles are the most sensitive to charge accumulation in dielectric layers. In contrast, thermally and electromagnetically actuated MEMS are much more radiation tolerant. MEMS operating on piezoresitive principles, while not showing any threshold for radiation sensitivity, do not fail catastrophically until doses of several Mrad are exceeded.

Techniques that eliminate or minimize charging effects include the following.

- A geometry change to eliminate the dielectric from between and under moving surfaces.

- A geometry change to minimize the exposed area of dielectric.

- A geometry change to reduce the sensitivity to trapped charge, e.g., stiffer restoring springs.

- Shielding, by covering exposed dielectric with a conductor as at well defined potential, as in Ref. 41.

- Change of dielectric material to one with lower trap density, see, e.g., Ref. 56.

- Adding a charge dissipation layer on the dielectric. ${ }^{57}$

- It is essential that all conductors be at well-defined potentials and not be allowed to float to avoid undesired electrostatic forces.
Reference 57 contains a detailed discussion of possible geometry changes, charge dissipation layers, and other approaches that can minimize the effect on device performance of charge that is trapped in dielectric films for electrostatic MEMS devices. The source of trapped charge in Ref. 57 is not from ionizing radiation, but from a high $\left(10^{8} \mathrm{~V} / \mathrm{m}\right)$ applied electric field, but the reasoning and mitigation techniques are the same.

Capacitive MEMS switches are probably the devices for which the most research has been done in charging, since charging due to charge injection from the electric field applied for normal operation is a main failure mode (see for instance Ref. 58). The same strategies used for $\mathrm{rf}$ switches, such as replacing dielectric films with arrays of dielectric posts, using pull-up electrodes, and selecting different dielectric materials, are all applicable to increasing radiation tolerance.

These radiation-hardening measures generally involve trade-offs. For instance, a stoichiometric $\mathrm{Si}_{3} \mathrm{~N}_{4}$ film is a much more ideal dielectric than the Si-rich $\mathrm{SiN}_{x}$ typically used in MEMS, but has much higher stress, trading off lower trap density for larger film stress. McCready et al. ${ }^{50}$ make the point that for piezoresistive devices, there is trade-off between the higher sensitivity obtained with lightly doped crystal, and the higher radiation tolerance of more disordered materials such as polysilicon.

Since electrothermal and electromagnetic actuation principles are intrinsically more radiation tolerant than electrostatic operation, these actuation principles should be considered for applications where high radiation doses are expected.

\section{Conclusions}

The growing acceptance of MEMS in safety critical applications on Earth (most notably accelerometers for airbag systems) as well as in consumer electronics (projection displays, accelerometers, gyroscopes, and pressure sensors) is a testament to the high level of reliability that can be achieved in suitably designed and packaged MEMS. Space presents a unique environment that may lead to additional failure modes, in particular due to radiation.

A review of the literature on the sensitivity of MEMS to radiation is presented. The main factor explaining the radiation sensitivity of MEMS devices is radiation-induced trapped charge in dielectrics, which can rapidly degrade the performance of MEMS operating on electrostatic principles. It should be noted that if failure occurs, it is generally at doses corresponding to several years to several hundreds of years of operation in orbit. Furthermore, the failure modes are well enough understood that effective mitigation strategies can be implemented to increase the radiation hardness of MEMS. While further research is needed into the effect of radiation on MEMS, radiation sensitivity will not be a limiting factor for widespread acceptance of MEMS in space applications.

\section{References}

1. "Phoenix Mars Mission," http://phoenix.lpl.arizona.edu/mission.php, accessed 14 Jun 2009. 
2. H. C. Koons, J. E. Mazur, R. S. Selesnick, J. B. Blake, J. F. Fennell, J. L. Roeder, and P. C. Anderson, "The impact of the space environment on space systems," Aerospace Corp., Report No. TR99(1670)-1 (20 July 1999).

3. SPENVIS, the Space Environment Information System, see http:// www.spenvis.oma.be/, accessed 14 Jun (2009).

4. A. Holmes-Siedle and L. Adams, Handbook of Radiation Effects, 2nd ed., Oxford University Press, Boston, MA (2002).

5. European Cooperation for Space Standardization, ESCC Basic Specification 22900 for Total Dose Steady-State Irradiation Test Method, see https://escies.org/ReadArticle?docId $=229$.

6. European Cooperation for Space Standardization, document ESCC Basic Specification 25100 for Single Event Effects Test Method and Guidelines, see https://escies.org/ReadArticle?docId=229.

7. B. Stark, "MEMS reliability assurance guidelines for space applications," JPL Publication 99-1 (1999).

8. T. George, "Overview of MEMS/NEMS technology development for space applications at NASA/JPL," Proc. SPIE 5116, 136-148 (2003).

9. European Cooperation for Space Standardization, ECSS-Q-60-11A Derating and End-of-Life Parameter Drifts-EEE Components, see http://www.ecss.nl/

10. S. Barthe, F. Pressecq, and L. Marchand, "MEMS for space applications: a reliability study," 4th Round Table on MNT for Space, 20-22 May 2003, paper 6.22, ESTEC, Noordwijk, Netherlands, see https:// escies.org/GetFile?rsrcid=1063.

11. R. Ghaffarian, D. G. Sutton, P. Chaffee, N. Marquez, A. K. Sharma, and A. Teverovsky, "Reliability of COTS MEMS accelerometer under shock and thermomechanical cycling," 2001 SMTA International Conference, Chicago, IL (30 Sep-4 Oct 2001).

12. A. K. Sharma and A. Teverovsky, "Evaluation of thermo-mechanical stability of COTS dual-axis MEMS accelerometers for space applications," NASA electronics parts and packaging program, EEE Links Newsletter (Jan. 2001), available at http://nepp.nasa.gov/eeelinks/ Jan2001/Alex Teverovsky/ Alex_Teverovsky/ MEMSaccelerometer p2 EEE.htm, accessed 14 Jun 2009.

13. D. Parrat et al., "The FAMARS Instrument: an atomic force microscope for the Phoenix Mission," 4th Intl. Conf. Mars Polar Science and Exploration, Davos, Switzerland, abstract 8047 (2006), see http://www.lpi.usra.edu/meetings/polar2006/pdf/8047.pdf.

14. "Radiant MEMS," http.//www.radantmems.com, accessed 14 Jun (2009).

15. J. Yao, C. Chien, R. Mihailovich, V. Panov, J. DeNatale, J. Studer, X. $\mathrm{Li}, \mathrm{A}$. Wang, and S Park, "Microelectromechanical system radio frequency switches in a picosatellite mission," Smart Mater. Struct. 10, 1196-1203 (2001).

16. I. De Wolf, M. van Spengen, X. Rottenburg, G. Carchon, P. Fiorini, A. Jourdaine, P. De Moor, and H. Tillmans, "Reliability of RFMEMS," 4th Round Table on MNT for Space, 20-22 May 2003 paper S6.5, ESTEC, Noordwijk, Netherlands, see https://escies.org/ GetFile?rsrcid=1066

17. S. Manhart, H. Schenk, M. Kiening, and L. Marchand, "Reliability assessment and lifetime testing with micro-mirrors," 4th Round Table on MNT for Space, 20-22 May 2003, paper S6.6, ESTEC, Noordwijk, Netherlands, see https://escies.org/GetFile?rsrcid=1067

18. J. Mitterauer, "Micropropulsion for small spacecraft: a new challenge for field effect electric propulsion and microstructured liquid metal ion sources," Surf. Interface Anal. 36(5-6), 380-386 (2002).

19. R. Krpoun and H. Shea, "Integrated out-of-plane nanoelectrospray thruster arrays for spacecraft propulsion," J. Micromech. Microeng. 19, 045019 (2009).

20. R. Krpoun, K. L. Smith, J. P. W. Stark, and H. R. Shea, "Tailoring the hydraulic impedance of out-of-plane micromachined electrospray sources with integrated electrodes," Appl. Phys. Lett. 94, 163502 (2009).

21. J. P. W. Lewis, Jr., S. W. Swanson, R. B. Cohen, and E. K. Antonsson, "Digital micropropulsion," Sens. Actuators, A 80(2), 143-154 (2000).

22. C. Rossi et al., "Matrix of $10 \times 10$ addressed solid propellant microthrusters: review of the technologies," Sens. Actuators, A 126, 241252 (2006)

23. J. Köhler, J. Bejhed, H. Kratz, F. Bruhn, U. Lindberg, K. Hjort, and L. Stenmark, "A hybrid cold gas microthruster system for spacecraft," Sens. Actuators, A A97-98, 587-98 (2002).

24. A. J. Ricco et al., "Integrated system to analyze the genetic effects of the space environment on living cells in culture: genesat," Proc. 9th Intl. Conf. Miniatur. Syst. Chem. Life Sci. ( $\mu$ TAS 2005), p. 527 (2005).

25. European Space Agency Procedures Standards and Specifications, document ESA PSS-01-609 (May 1993) Radiation Design Handbook, see https://escies.org/ReadArticle?docId=263.

26. European Cooperation for Space Standardization, document ECSS E-ST-10-04C Space environment, see http://www.ecss.nl/forums/ ecss/dispatch.cgi/standards/showFile/100700/d20081115082809/No/ ECSS-E-ST-10-04C(15November2008).pdf.
27. M. Beasley, S. L. Firebaugh, R. L. Edwards, A. C. Keeney, and R. Osiander, "MEMS thermal switch for spacecraft thermal control," Proc. SPIE 5344, 98-105 (2004)

28. S. Arney, "Designing for MEMS reliability," MRS Bull. 2001, 296, Apr. 2001.

29. O. Tabata, T. Tsuchiya, O. Brand, G. Fedder, C. Hierold, and J. Korvink, Eds., Reliability of MEMS: Testing of Materials and Devices, Advanced Micro and Nanosystems series, Wiley-VCH, New York (2008).

30. A. Hartzell and D. Woodilla, "MEMS reliability, characterization, and test," Proc. SPIE 4558, 1-5 (2001).

31. H. Shea, "Reliability of MEMS for space applications," Proc. SPIE 6111, 61110A (2006)

32. L. D. Edmonds, G. M. Swift, and C. I. Lee, "Radiation response of a MEMS accelerometers: an electrostatic force," IEEE Trans. Nucl. Sci. 45, 2779-2788 (1998).

33. C. I. Lee, A. H. Johnston, W. C. Tang, and C. E. Barnes, "Total dose effects on micromechanical systems (MEMS): accelerometers," IEEE Trans. Nucl. Sci. 43, 3127-3132 (1996).

34. S. McClure, L. Edmonds, R. Mihailovich, A. Johnston, P. Alonzo, J. DeNatale, J. Lehman, and C. Yui, "Radiation effects in microelectromechanical systems (MEMS): RF relays," IEEE Trans. Nucl. Sci. 49 , 3197-3202 (Dec. 2002).

35. L. P. Schanwald, J. R. Schwank, J. J. Sniegowski, D. S. Walsh, N. F. Smith, and K. A. Peterson, "Radiation effects on surface micromachined comb drives and microengines," IEEE Trans. Nucl. Sci. 45(6), 2789-2798 (1998)

36. A. Neels, A Dommann, A. Schifferle, O. Papes, and E. Mazza, "Reliability and failure in single crystal silicon MEMS devices," Microelectron. Reliab. 48, 1245-1247 (2008).

37. A. Dommann, A. Enzler, and N. Onda, "Advanced X-ray analysis techniques to investigate aging of micromachined silicon actuators for space application," Microelectron. Reliab. 43, 1099-1103 (2003).

38. J. R. Vig, "Introduction to quartz frequency standards," SLCET-TR92-1 (Rev. 1) (1992), see http://www.iee-uffc.org/freqcontrol/quartz/ vig/vigtoc.htm.

39. A. Tazzoli,G. Cellere, V. Peretti, A. Paccagnella, and G. Meneghesso, "Radiation sensitivity of OHMIC RF-MEMS switches for spatial applications, in Proc. 22nd Intl. Conf. Micro Electro Mechan. Syst (MEMS), pp. 634-637(2009).

40. V. Theonas, M. Exarchos, G. J. Papaioannou, and G. Konstantinidis, "RF MEMS dielectric sensitivity to electromagnetic radiation," Sens. Actuators, A 132, 25-33 (2006).

41. A. R. Knudson, S. Buchner, P. McDonald, W. J. Stapor, A. B. Campbell, K. S. Grabowski, and D. L. Knies, "The effects of radiation on MEMS accelerometers," IEEE Trans. Nucl. Sci. 43, 3122-3126 (1996).

42. O. Coumar, P. Poirot, R. Gaillard, E. Miller, N. Buard, and L. Marchand, "Total dose effects and SEE screening on MEMS COTS accelerometers," IEEE Radiation Effects Data Workshop, Atlanta, GA, 22 Jul 2004, pp. 125-129 (2004).

43. G. Quadri, J. M. Nicot, G. Guibaud, and O. Gilard, "Optomechanical microswitch behavior in a space radiation environment," IEEE Trans. Nucl. Sci. 52(5), 1795-1799 (2005).

44. R. N. Schwartz, "Gamma-ray radiation effects on RF MEMS switches," Proc. 2000 IEEE Microelectron. Reliability and Oual. Workshop, Glendale, CA, 31 Oct 2000, p. IV.6 (2000).

45. T. F. Miyahira, H. N. Becker, S. S. McClure, L. D. Edmonds, A. H. Johnson, and Y. Hishinuma, "Total dose degradation of MEMS optical mirrors," IEEE Trans. Nucl. Sci. 50(6), 1860-1866 (2003).

46. S. Buchner et al., "Response of a MEMS Microshutter operating at $60 \mathrm{~K}$ to ionizing radiation," IEEE Trans. Nucl. Sci. 54(6), 2463-2467 (2007).

47. J. R. Caffey and P. E. Kladitis, "The effects of ionizing radiation on microelectromechanical systems (MEMS) actuators: electrostatic, electrothermal, and bimorph," Micro Electro Mechan. Syst. 17th IEEE Intl. Conf. (MEMS), Maastricht, The Netherlands, 25-29 Jan 2004, pp. 133-136 (2004)

48. K. E. Holbert, J. A. Nessel, S. S. McCready, A. S. Heger, and T. H. Harlow, "Response of piezoresistive MEMS accelerometers and pressure transducers to high gamma dose," IEEE Trans. Nucl. Sci. 50(6) 1852-1859 (2003)

49. D. G. Marinaro, P. McMahon, and A. Wilson "Proton radiation effects on MEMS silicon strain gauges," IEEE Trans. Nucl. Sci. 55(3), 1714 (2008).

50. S. S. McCready, T. H. Harlow, A. S. Heger, and K. E. Holbert "Piezoresistive micromechanical transducer operation in a pulsed neutron and gamma ray environment," IEEE Rad. Effects Data Workshop, Phoenix, AZ, 15-19 Jul 2002, pp. 181-186 (2002).

51. S. Y. Zhu, Y. P. Huang, J. Wang, A. Z. Li, S. Q. Shen, and M. H. Bao, "Total dose radiation effects of pressure sensors fabricated on Unibond-SOI materials," Nucl. Sci. Technol. 12, 209-214 (2001)

52. C. L. Allred, J. T. Borenstein, and L. W. Hobbs, "Neutron irradiationinduced dimensional changes in MEMS glass substrates," Nucl. Instrum. Methods Phys. Res. B 264, 66-72 (2007). 
53. M. J. Key, V. Cindro, and M. Lozano, "On the radiation tolerance of SU-8, a new material for gaseous microstructure radiation detector fabrication," Radiat. Phys. Chem. 71, 1003-1007 (2004).

54. J. Ruan, E. Papandreou, M. Lamhamdi, M. Koutsoureli, F. Coccetti, P. Pons, G. Papaioannou, and R. Plana, "Alpha particle radiation effects in RF MEMS capacitive switches," Microelectron. Reliab. 48, 1241-1244 (2008)

55. E. Papandreou, M. Lamhamdi, C. M. Skoulikidou, P. Pons, G. Papaioannou, and R. Planaet al., "Structure dependent charging process in RF MEMS capacitive switches," Microelectron. Reliab. 47, 18121817 (2007).

56. M. Lamhamdi, L. Boudou, J. Gustavino, Y. Segui, P. Pons, B. Rousset, and R. Plana, "Characterization of dielectric-charging effects in PECVD nitrides for use in RF MEMS capacitive switches," Proc. 7th Intl. Conf. RF MEMS RF Microsyst. (MEMSWAVE), Orvieto, Italy, 27-30 Jun 2006 (2006).

57. H. R. Shea, A. Gasparyan, H. B. Chan, S. Arney, E. E. Frahm, D. López, S. Jin, and R. P. McConnell, "Effects of electrical leakage currents on MEMS reliability and performance," IEEE Trans. Device Mater. Reliab. 4(2), 198-207 (2004).

58. W. M. van Spengen, R. Puers, R. Mertens, and I. De Wolf, "A comprehensive model to predict the charging and reliability of capacitive RF MEMS switches," J. Micromech. Microeng. 14, 514-521 (2004).
59. C. Son and B. Ziaie, "An implantable wireless microdosimeter for radiation oncology," Proc. IEEE Conf. Micro Electro Mechan. Syst. (MEMS 2008), Tucson, AZ, 15-19 Jul 2002, p. 256 (2008).

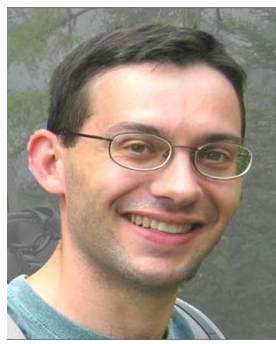

Herbert R. Shea holds a PhD (1997) in physics from Harvard University, and a BSc in physics from McGill University. After two years as a postdoctorate at IBM's T.J. Watson Research Center, he joined Lucent Technologies' Bell Laboratories in Murray Hill, New Jersey, where he became the technical manager of the Microsystems Technology group. Since April 2004, he has been an assistant professor at the EPFL in

Lausanne, Switzerland, where he founded the Microsystems for Space Technologies Laboratory. Current research topics include micromachined polymer MEMS (artificial muscles), electric micropropulsion, MEMS sensors for satellite attitude determination, chip-scale plasma sources, and radiation sensitivity of MEMS. 